\title{
A central role for glial CCR5 in directing the neuropathological interactions of HIV-1 Tat and opiates
}

Sarah Kim', Yun Kyung Hahn' ${ }^{1}$, Elizabeth M Podhaizer ${ }^{2}$, Virginia D McLane ${ }^{2}$, Shiping Zou ${ }^{1,4}$, Kurt F Hauser ${ }^{1,2,3}$ and Pamela E Knapp ${ }^{1,2,3^{*}}$

\section{Abstract}

Background: The collective cognitive and motor deficits known as HIV-associated neurocognitive disorders (HAND) remain high even among HIV+ individuals whose antiretroviral therapy is optimized. HAND is worsened in the context of opiate abuse. The mechanism of exacerbation remains unclear but likely involves chronic immune activation of glial cells resulting from persistent, low-level exposure to the virus and viral proteins. We tested whether signaling through C-C chemokine receptor type 5 (CCR5) contributes to neurotoxic interactions between HIV-1 transactivator of transcription (Tat) and opiates and explored potential mechanisms.

Methods: Neuronal survival was tracked in neuronal and glial co-cultures over $72 \mathrm{~h}$ of treatment with HIV-1 Tat \pm morphine using cells from CCR5-deficient and wild-type mice exposed to the CCR5 antagonist maraviroc or exogenously-added BDNF (analyzed by repeated measures ANOVA). Intracellular calcium changes in response to Tat \pm morphine \pm maraviroc were assessed by ratiometric Fura- 2 imaging (analyzed by repeated measures ANOVA). Release of brain-derived neurotrophic factor (BDNF) and its precursor proBDNF from CCR5-deficient and wild-type glia was measured by ELISA (analyzed by two-way ANOVA). Levels of CCR5 and $\mu$-opioid receptor (MOR) were measured by immunoblotting (analyzed by Student's $t$ test).

Results: HIV-1 Tat induces neurotoxicity, which is greatly exacerbated by morphine in wild-type cultures expressing CCR5. Loss of CCR5 from glia (but not neurons) eliminated neurotoxicity due to Tat and morphine interactions. Unexpectedly, when CCR5 was lost from glia, morphine appeared to entirely protect neurons from Tat-induced toxicity. Maraviroc pre-treatment similarly eliminated neurotoxicity and attenuated neuronal increases in $\left[\mathrm{Ca}^{2+}\right]_{\mathrm{i}}$ caused by Tat \pm morphine. proBDNF/BDNF ratios were increased in conditioned media from Tat \pm morphine-treated wild-type glia compared to CCR5-deficient glia. Exogenous BDNF treatments mimicked the pro-survival effect of glial CCR5 deficiency against Tat \pm morphine.

Conclusions: Our results suggest a critical role for glial CCR5 in mediating neurotoxic effects of HIV-1 Tat and morphine interactions on neurons. A shift in the proBDNF/BDNF ratio that favors neurotrophic support may occur when glial CCR5 signaling is blocked. Some neuroprotection occurred only in the presence of morphine, suggesting that loss of CCR5 may fundamentally change signaling through the MOR in glia.

Keywords: Human immunodeficiency virus, Morphine, C-C chemokine receptor 5, Maraviroc, Brain-derived neurotrophic factor, NeuroHIV

\footnotetext{
* Correspondence: pamela.knapp@vcuhealth.org

${ }^{1}$ Department of Anatomy and Neurobiology, Virginia Commonwealth

University School of Medicine, 1217 E. Marshall St, Richmond, VA 23298-0709,

USA

2Department of Pharmacology and Toxicology, Virginia Commonwealth

University, Richmond, VA 23298, USA

Full list of author information is available at the end of the article
}

(c) The Author(s). 2018 Open Access This article is distributed under the terms of the Creative Commons Attribution 4.0 International License (http://creativecommons.org/licenses/by/4.0/), which permits unrestricted use, distribution, and

reproduction in any medium, provided you give appropriate credit to the original author(s) and the source, provide a link to the Creative Commons license, and indicate if changes were made. The Creative Commons Public Domain Dedication waiver (http://creativecommons.org/publicdomain/zero/1.0/) applies to the data made available in this article, unless otherwise stated. 


\section{Background}

Human immunodeficiency virus type 1 (HIV-1) remains a global epidemic [1]. Despite significant antiretroviral suppression of $\mathrm{HIV}-1$ propagation in the periphery, limited penetration of combination antiretroviral therapy (cART) drugs through the blood-brain barrier [2, 3] as well as the early viral integration into the host genome cultivates a reservoir in which low levels of viral replication can be sustained in the central nervous system (CNS) [4-6]. Thus, HIV-1+ individuals are especially vulnerable to $\mathrm{CNS}$ injury, which afflicts as many as $50 \%$ of this population [7-9]. The neurological consequences of HIV-1 infection are known collectively as HIVassociated neurocognitive disorders (HAND). HAND presents as a spectrum of deficits ranging from mild or asymptomatic cognitive disorders to severe, HIVassociated dementia and includes a variety of cognitive, behavioral, and/or motor symptoms [10]. Postmortem findings in HIV-infected individuals, even those effectively treated with cART, often include signs of prominent CNS inflammation, such as increased numbers and/ or activation of microglia and astroglia, perivascular inflammation, and leukocytic infiltration resulting in marked neuronal degeneration [11-13]. Notably, neuronal injury and alterations in signaling are not accompanied by direct viral infection of neurons [14-16]. Instead, microglia and macrophages are the major source of productive viral infection in the CNS [17-19]. Small numbers of astrocytes are infected and can produce toxic proteins that injure bystander neurons, but they have not been reliably shown to produce virus [20, 21]. These combined findings highlight the importance of glial impact on neurons, which is normally critical in maintaining proper neuronal activity and survival and suggests a mode of indirect injury that is a consequence of the innate CNS immune response to HIV.

HIV-1 infection and injection drug use are interlinked epidemics, due in large part to needle sharing and increased risky sexual behavior. Because heroin (diacetyl morphine) is widely abused and its active metabolite, morphine, is an opiate prescribed for pain syndromes experienced by HIV patients, we and others are interested in neurological interactions of HIV-1 and heroin/morphine. The comorbid effects of $\mathrm{HIV}$ and opiates are not trivial. HIV+ individuals who also abuse opiates demonstrate more severe neuropathology than those who do not, and these findings can translate to exacerbated and accelerated HAND [22-25]. The actions of morphine in this context occur primarily through the activation of $\mu$-opioid receptors (MORs) expressed on glial cells. MOR activation results in the potentiation of HIV-induced release of pro-inflammatory factors (e.g., TNF $\alpha, \mathrm{IL}-1 \beta$, IL-6, CCL5, and CCL2), as well as oxidative and nitrosative stress, mitochondrial dysregulation, elevated intracellular calcium levels, and excess extracellular glutamate (via restriction of astroglial glutamate uptake), all of which promote neurotoxicity [26-30]. Dysregulated release of inflammatory factors upon chronic exposure to viral proteins may recruit and activate more immune cells, propagating a cycle of increasing inflammation with significant downstream neuronal consequences.

One receptor vulnerable to the aforementioned dysregulation by $\mathrm{HIV}$ infection is $\mathrm{C}-\mathrm{C}$ chemokine receptor 5 (CCR5). CCR5 is widely expressed on T lymphocytes, macrophages, microglia, and dendritic cells and plays a critical role in inducing migration of immune cells to sites of infection and injury in response to elevated levels of certain C-C-chemokine ligands (MIP-1 $\alpha / C C L 3$, MIP$1 \beta /$ CCL4, CCL5/RANTES) [31]. CCR5 and its ligands are upregulated during HIV infection, leading to excess activation of CCR5-expressing cells, including CNS microglia and astrocytes [32, 33]. A homozygous deletion of 32 base pairs in the CCR5 gene prevents its expression on the cell surface and confers improved but not absolute immunity to infection with R5-tropic strains of HIV-1 [34]. Individuals carrying the allele show slowed disease progression upon infection with HIV and less cognitive impairment [35-38]. Furthermore, maraviroc, a CCR5 antagonist with relatively high CNS penetrance [39], reduces microglial activation in the simian immunodeficiency virus-infected model to uninfected control levels and reduces the expression of several pro-inflammatory factors [40]. cART regimens that are supplemented with maraviroc improve the neurocognitive status of $\mathrm{HIV}+$ patients and reduce CSF levels of TNF $\alpha[41,42]$. Morphine can alter CCR5 expression by monocytes and activated $\mathrm{T}$ cells, contributing to increased viral entry and replication, and excess CNS immune activation [43, 44]. We previously demonstrated that loss of CCL5, a CCR5 ligand, prevented widespread glial activation and reduced levels of another inflammatory ligand (CCL2), suggesting CCL5 may be an upstream activating signal that promotes the expansion of downstream pro-inflammatory responses [45]. The present studies investigate whether interrupting CCR5 signaling may protect neurons against the comorbid effects of HIV-1 and opiate exposure, apart from any effect of blocking HIV entry. We demonstrate using mixed glial-neuronal co-cultures that morphine potentiates Tat-induced neuronal death and that a loss of CCR5 expression on glial cells rescues neurons from such enhanced neurotoxicity. Surprisingly, morphine completely protected against Tat neurotoxicity in cultures with CCR5-null glia even though Tat by itself was still toxic. Levels of brain-derived neurotrophic factor (BDNF) are reduced in $\mathrm{HIV+}$ individuals and by glycoprotein 120 
(gp120), an HIV-1 envelope protein with neurotoxic properties $[46,47]$. We found that the ratio of neurotrophic BDNF to its neurotoxic precursor (proBDNF) was altered in CCR5-null glia exposed to Tat and morphine co-treatment such that the environment favored neuronal support. BDNF also rescued neurons from Tat + morphine neurotoxicity in a manner similar to the loss of glial CCR5 expression. Overall, we postulate that CCL5/CCR5 signaling is a point of convergence for opiate-Tat interactions within the inflammatory milieu of the HIV-infected CNS. Blocking CCR5 appears to enhance neuroprotection, perhaps by increasing BDNFrelated neuroprotection. Inactivation or loss of CCR5 may also change heterologous interactions between MOR and CCR5 related to toxicity and protection.

\section{Methods}

Experiments were conducted in compliance with procedures reviewed and approved by the Virginia
Commonwealth University Institutional Animal Care and Use Committee.

\section{CCR5-null mice}

Transgenic mice in which there has been a loss in CCR5 expression were obtained from Jackson Labs (Bar Harbor, ME) and maintained as homozygous breeding trios. Briefly, the insertion of a neomycin resistance gene to replace the single coding exon has resulted in the constitutive loss of CCR5 expression. To confirm the loss of CCR5, tail snips and harvested glial cells were digested and DNA was isolated as per the instructions of the manufacturer (KAPA Mouse Genotyping; KAPA Biosystems; Wilmington, MA). Primer sets designed to identify the neomycin resistance gene as well as the CCR5 coding exon were obtained from Jackson Labs. Polymerase chain reaction was carried out to confirm the presence of the neomycin resistance gene and the absence of the CCR5 sequence (Fig. 1a). Because the
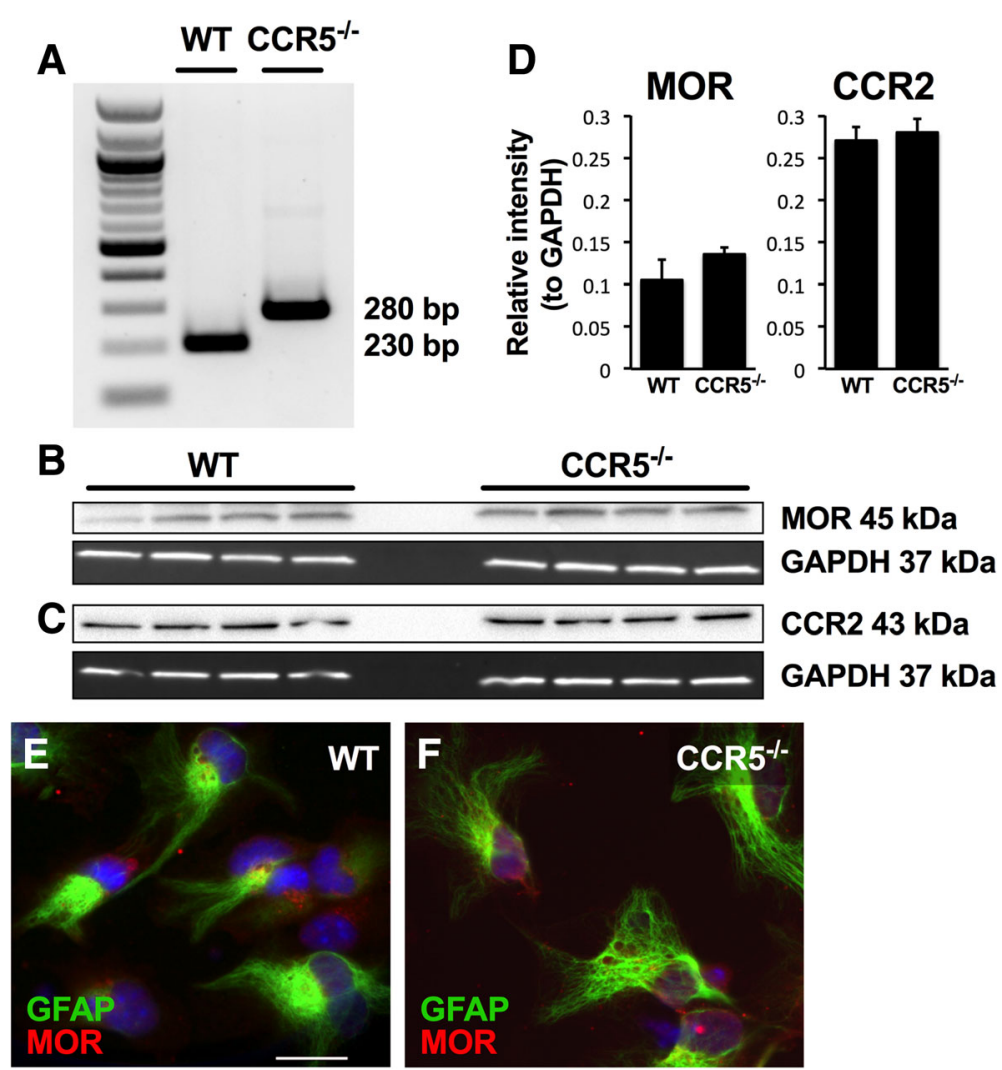

Fig. 1 Expression of MOR and CCR2 are not altered in cell cultures derived from CCR5-null mice. a The CCR5 knockout was verified by the presence of a 280-bp band that represents the neomycin resistance gene insertion into the single coding exon of the receptor. A 230-bp band indicates the presence of the CCR5 receptor in wild-type mice. A 100-bp ladder is shown for reference. $\mathbf{b}, \mathbf{c}$ MOR and CCR2 protein levels were assessed in both wild-type and CCR5-deficient glia and normalized against GAPDH. d Statistical comparison (two-tailed Student's $t$ test) demonstrated no significant difference between genotypes in levels of either receptor. $\mathbf{e}, \mathbf{f}$ Immunocytochemistry of wild-type (e) and knockout (f) glia show similar expression of MOR (red) in GFAP+ (green) astrocytes. Astrocyte morphology varies widely in the cultures. MOR appears as a punctate distribution along the cell surfaces as well as in cytoplasmic areas. Scale bar $=20 \mu \mathrm{M}$ 
knockout is global, CCR5-deficient glia or neurons are reconstituted into co-cultures with wild-type neurons or glia, respectively, to study effects of mutations in a single cell type. Mice of the C57Bl6/J background strain were used as wild-type controls. The CCR5-null mice displayed no overt signs of illness or problems during development, and litters occur in a similar frequency and size as the $\mathrm{C} 57 \mathrm{Bl} / \mathrm{J}$ strain.

\section{Primary co-cultures of mixed glia and striatal neurons}

Mixed glial cultures (approximately 90\% astroglia, 8\% microglia, and $2 \%$ glial progenitors/incipient oligodendroglia [30]) were obtained from C57Bl6/J or CCR5-deficient pups at $0-1$ day postnatal. Whole brains were dissected, minced, and incubated with tryp$\sin (2.5 \mathrm{mg} / \mathrm{ml})$ and DNase $(0.015 \mathrm{mg} / \mathrm{ml})$ in Dulbecco's modified Eagle's medium (Invitrogen, Carlsbad, CA; $30 \mathrm{~min}, 37^{\circ} \mathrm{C}$ ). Tissue was resuspended in medium containing 10\% fetal bovine serum (Hyclone, Logan, UT), triturated, and filtered twice through $100 \mu \mathrm{m}$ and $40 \mu \mathrm{m}$ pore nylon mesh, then plated onto poly-LLysine-coated (Sigma-Aldrich, St Louis, MO; $0.5 \mathrm{mg} / \mathrm{ml}$ ) 24-well plates at a density of $75 \times 10^{3}$ cell/well. Glia reached confluency after 7-8 days, after which neurons were plated onto their surface.

Neurons were cultured from striata dissected from C57Bl6/J or CCR5-deficient mice at gestational days 1517. Tissue was incubated $\left(30 \mathrm{~min}, 37^{\circ} \mathrm{C}\right)$ with trypsin $(2.5 \mathrm{mg} / \mathrm{ml})$ and DNase $(0.015 \mathrm{mg} / \mathrm{ml})$ in neurobasal medium (Invitrogen), supplemented with B-27 (Invitrogen), L-glutamine $(9.5 \mathrm{mM}$; Invitrogen), glutamate (25 $\mu \mathrm{M}$; Sigma), and antibiotic/antimycotic solution containing penicillin, streptomycin, and amphotericin B (Invitrogen). After centrifugation, the tissue was triturated and filtered twice through a $70 \mu \mathrm{m}$ pore nylon mesh to achieve a single-cell suspension. The cells were then plated on top of a bed of confluent glia at $25 \times 10^{3}$ cells/well, and the co-cultures were grown for another 7-8 days in the supplemented neurobasal medium. At this point, the neurons were relatively mature, as previously assessed by the expression of microtubuleassociated protein 2 and an array of receptors such as NMDA-R and, importantly, the opiate receptors. Mature neurons also take on a distinct morphology compared to neural progenitor cells, possessing a larger cell body with a prominent nucleus and established axonal and dendritic processes.

\section{Repeated measures assessment}

Each plate was maintained in a temperature-controlled, $\mathrm{CO}_{2}$-regulated chamber $\left(37{ }^{\circ} \mathrm{C}, 5 \% \mathrm{CO}_{2}\right)$ in a heat insert MXX holder (PeCon Instruments, Erbach, Germany) and placed on the scanning stage of a Zeiss Axio Observer Z1 inverted microscope (Carl Zeiss, Inc., Thornwood,
$\mathrm{NY}$ ). Five to ten non-overlapping fields, each containing five to ten striatal neurons, were selected from each well based on distinctive neuronal morphology, including features listed in the previous section. Time-lapse images of the selected fields were recorded in 1-h intervals for $72 \mathrm{~h}$ using an automated, computer-controlled stage encoder and Axiovision 4.6 software (Carl Zeiss, Inc.). Pre-selected neurons were followed over the 72-h time course and assessed for survival in each hourly image. Neuronal death was determined through morphological criteria, including neurite disintegration, loss of phase brightness, and involution or complete fragmentation of the cell body, all of which were present in each cell counted for analysis (Fig. 2). The number of viable neurons was binned into 4-h intervals for analysis (see the "Statistical Methods" section).

\section{Intracellular calcium assessment}

Co-cultures of mixed glia and neurons were prepared on 12-well glass-bottom MatTek (Ashland, MA) plates for calcium imaging. Cells were loaded with $1-\mu \mathrm{M}$ Fura-2 AM (Invitrogen, Carlsbad, CA) suspended in DMSO for $30 \mathrm{~min}$ then washed. This concentration was optimized for minimal astrocyte loading to reduce background signals. The plate was incubated for $30 \mathrm{~min}$ in a temperature- and $\mathrm{CO}_{2}$-regulated chamber $\left(37{ }^{\circ} \mathrm{C}, 5 \%\right.$ $\mathrm{CO}_{2}$ ) to ensure de-esterification of the acetoxy methylester (AM) group. On a computer-controlled stage embedded in a Zeiss Axio Observer Z1 microscope, two 20X fields containing five to ten neurons were identified in each well and imaged using Zeiss Zen software (Carl Zeiss Microscopy, LLC, Thornwood, NY). Cells were treated with Tat \pm morphine \pm maraviroc, and a series of fluorescent images of the same neurons (excitation at 340 and $380 \mathrm{~nm}$, emission at $510 \mathrm{~nm}$ ) was taken every $15 \mathrm{~min}$ for $1 \mathrm{~h}$. Two regions of interest (ROIs; each 1520 pixels), positioned to avoid both the nucleus and margins of the cell, were selected within the scant cytoplasm of all neurons. ROIs were selected in neurons based on Fura-2 loading but prior to ratiometric imaging.

\section{HIV-1 Tat and drug treatments}

Cultures were treated with Tat ${ }_{1-86}$ Clade IIIB $(1.2 \mathrm{ng} / \mu \mathrm{l}$; ImmunoDiagnostics, Woburn, MA), morphine sulfate (500 nM; NIDA Drug Supply System), the broadspectrum opioid receptor antagonist naloxone $(1.5 \mu \mathrm{M}$; Sigma), or maraviroc (50 nM; BOC Sciences, Shirley, $\mathrm{NY}$ ), a small molecule, allosteric inhibitor of CCR5, as well as a number of drug combinations. Tat and morphine were added concurrently; naloxone and maraviroc were given $1 \mathrm{~h}$ prior to Tat and morphine treatments. To explore compensatory repercussions of a constitutive knockout, we compared maraviroc treatments to CCR5- 


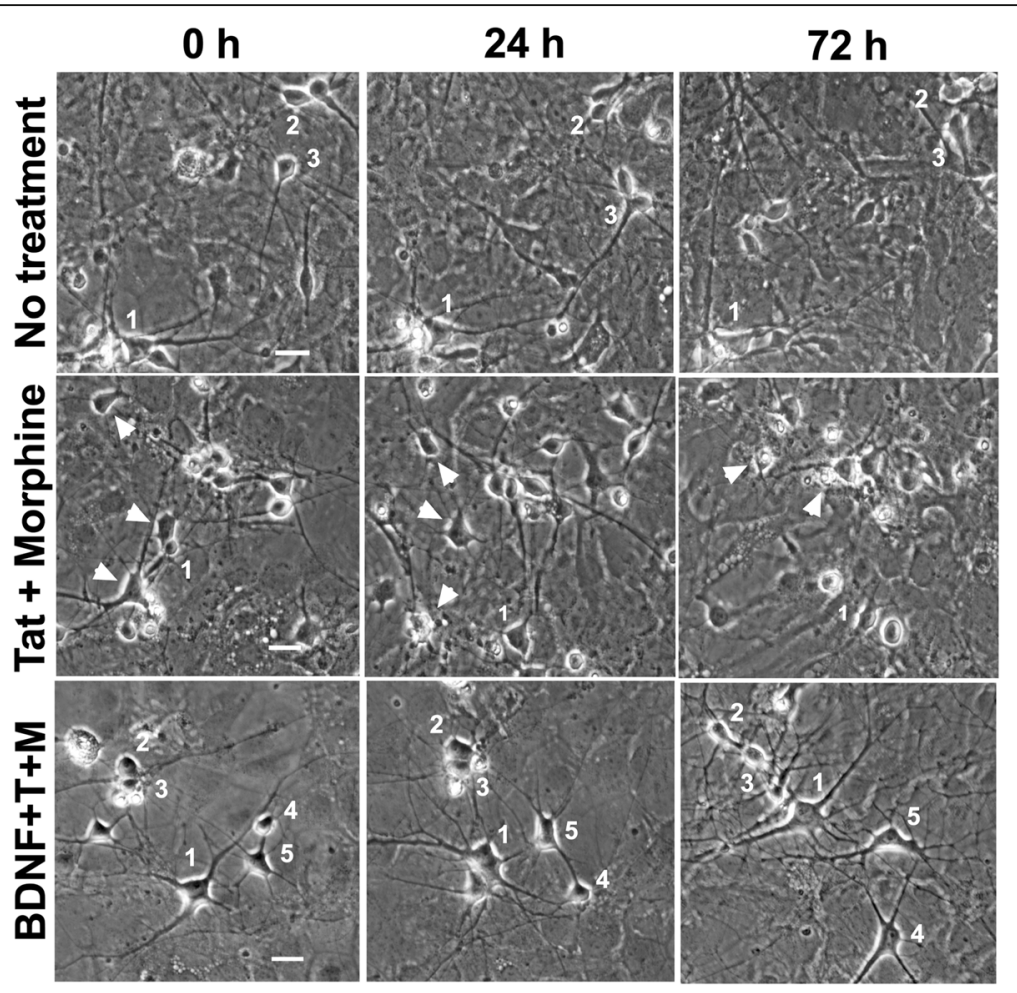

Fig. 2 Representative time-lapse images track neuronal fate. Time-lapse images of co-cultures of wild-type neurons and glia were taken every hour to track neuron survival. The fate of individual neurons can be tracked over time by following the labeled number in the image. Neurons were pre-selected in the image taken at $0 \mathrm{~h}$ and followed for the duration of the experiment or until time of death. Death was determined using a set of rigorous morphological criteria including loss of phase brightness, fragmentation of neurites, and collapse of the cell soma (white arrowheads). Representative images from three treatment groups (no treatment, Tat + morphine, BDNF + Tat + morphine) are shown here. Wells receiving no treatment typically showed $85-90 \%$ survival rates. Data in Figs. 3 and 6 show that Tat + morphine treatment results in a higher frequency of neuron death by $72 \mathrm{~h}$, and BDNF rescues neurons from the death induced by Tat + morphine treatment. Scale bars for each set of panels $=20 \mu \mathrm{M}$

deficient cultures in two different paradigms. In short-term experiments, maraviroc was added immediately prior to the start of the time-lapse imaging. In long-term experiments, maraviroc was added to the media for the duration of the co-culture maturation and imaging period (approximately 2 weeks) and refreshed every 2-3 days. The Tat concentration was chosen based on prior studies that similarly showed neuron death within the $72-\mathrm{h}$ period [30]. Morphine, naloxone, and maraviroc concentrations were based on previous studies from this lab and chosen to produce full receptor occupancy or antagonism. BDNF (50 ng/ml) was purchased through Sigma-Aldrich.

\section{ELISA}

C57 wild-type or CCR5-deficient glia were matured for 7-8 $\mathrm{d}$ and then treated with Tat and/or morphine for 6 or $24 \mathrm{~h}$. Media was harvested and immediately stored in $-80{ }^{\circ} \mathrm{C}$. The conditioned media were assessed for BDNF (Abcam, Cambridge, UK) and proBDNF (Biosensis, Thebarton, Australia) by ELISA according to manufacturers' instructions. $3,3^{\prime}, 5,5^{\prime}$-tetramethylbenzidine substrate was added for color development, and plates were read at $450 \mathrm{~nm}$ on a SpectraMax M2 microplate reader (Molecular Devices, San Jose, CA) immediately after terminating the reaction, then analyzed using SoftPro Max 1.6 software. BDNF and proBDNF levels were determined based on a standard curve.

\section{Immunoblotting}

CCR2 and MOR proteins were assessed in cultured wild-type C57 and CCR5-knockout glial cells. Cells were harvested in lysis buffer containing $1 \times$ Tris-buffered saline (TBS), 1\% NP-40, 1\% Triton X-100, 1 mM PMSF, $10 \%$ glycerol, and Halt Protease Inhibitor Cocktail (Thermo Fisher Scientific, Waltham, MA), centrifuged (15 min, 40,000 rpm) and stored at $-80{ }^{\circ} \mathrm{C}$ until use. Protein concentration of each sample was measured using the BCA protein assay (Thermo Fisher Scientific). Forty $\mu \mathrm{g}$ of protein lysates were loaded into each well of a 4-20\% Tris-HCl Ready Gel (Bio-Rad Laboratories, Hercules, CA) along with Precision Plus Protein Dual Color Standards (Bio-Rad; MW range 10-250 kDa) to visualize protein transfer and determine molecular 
weight. Proteins were transferred to PVDF membranes (Bio-Rad). Antibodies to CCR2 (1:1000, Abcam), MOR (1:1000, Antibodies Incorporated), and GAPDH (1:2000, Abcam) were used to probe the blots. Fluorescent secondary antibodies were then visualized on a ChemiDoc Gel Imaging system and analyzed with Bio-Rad Image Lab Software 5.2.1. CCR2 and MOR values were normalized to GAPDH.

\section{Immunocytochemistry}

Wild-type and CCR5-deficient glial cultures were grown to confluence on glass coverslips, fixed in $4 \%$ paraformaldehyde and permeabilized $(0.1 \%$ Triton X-100, $1 \%$ normal goat serum) for 15 min. After blocking for $1 \mathrm{~h}$ ( $1 \%$ normal goat serum, $0.1 \%$ BSA), primary antibodies to GFAP (1:1000, Millipore) and MOR (1:500, Antibodies Incorporated, Davis, CA) were used to label astrocytes and MOR, after which nuclei were identified by the Hoechst 33342 stain $(1: 20,000)$. Coverslips were mounted on glass microscope slides with Prolong Gold anti-fade reagent (Invitrogen).

\section{Statistical methods}

Time-lapse studies tracking neuron survival were analyzed by repeated measures ANOVA (Graph Pad Prism 7). The number of viable neurons was binned into 4-h intervals and analyzed to compare treatment effects. Bonferroni's post hoc test was used to determine group differences following confirmation of main effects. Findings are presented as a mean percentage of viable neurons relative to the total number of pre-selected neurons. Intracellular calcium levels were calculated as a percent of control, defined as untreated neurons measured at baseline. Mean effects of Tat \pm morphine \pm maraviroc on $\left[\mathrm{Ca}^{2+}\right]_{i}$ in individual neurons were analyzed at 15-min intervals up to $1 \mathrm{~h}$ using repeated measures ANOVA with Duncan's post hoc testing (Statistica 13.2, Dell Inc., Tulsa, OK). ELISA results were analyzed using two-way ANOVA followed by Fisher's PLSD post hoc testing to assess individual group differences. Protein expression levels of MOR and CCR2 were statistically compared using a two-tailed Student's $t$ test. An alpha level of $p \leq 0.05$ was considered significant for all tests. Data are expressed as mean values \pm standard error of the mean (SEM).

\section{Results}

Characterization of CCR5, MOR, and CCR2 expression in wild-type and CCR5-deficient cultures

DNA and protein analysis were used to characterize expression of CCR5, MOR, and CCR2 in both wild-type and CCR5-deficient mixed glial cultures. We first confirmed that cultures derived from CCR5-null transgenic mice did not express CCR5 using PCR (Fig. 1a). Western blots showed that MOR protein levels did not differ between wild-type and CCR5-null glial cultures when MOR expression was examined as a fraction of GAPDH (Fig. 1b, d). Immunocytochemical labeling of astrocytes expressing both GFAP and MOR demonstrates similar morphological distribution of MOR irrespective of CCR5 expression, namely, both cytoplasmic and more superficial punctate distribution near the cell body and along processes (Fig. 1e, f). Because of the constitutive loss of CCR5 in the transgenic mice, expression of a closely related chemokine receptor, CCR2, was examined to investigate the possibility of compensatory co-regulation. Western blot analysis showed no differences in CCR2 expression across several samples $(n=4)$ of wild-type and CCR5-null glia (Fig. 1c, d). Relative intensities for both CCR2 and MOR were quantified (Fig. 1d) and analyzed using a two-tailed Student's $t$ test.

\section{Enhanced HIV-1 Tat and opiate neurotoxicity reversed by loss of glial CCR5}

In order to investigate the role of CCR5 in mediating the neurotoxic interactions between Tat and morphine, we established a series of co-cultures in which the glia, neurons, or both lacked CCR5. Representative images shown in Fig. 2 illustrate the fate of selected neurons when tracked over the 72-h trial. Using C57Bl6/J wildtype co-cultures, we confirmed that Tat is neurotoxic and that interactions with morphine enhanced Tatinduced toxicity over a 72-h period [30] (Fig. 3a). These effects appear to be mediated by opioid receptors, most likely MOR, since pre-treatment with the broadspectrum opioid receptor antagonist naloxone eliminated Tat and morphine interactions. In cultures where glia did not express CCR5, exposure to Tat by itself still led to significant levels of neurotoxicity (Fig. 3b). However, the presence of morphine had unexpected effects. When CCR5 was absent from glia, the neurons were protected from Tat and morphine interactions as hypothesized. Surprisingly, in the presence of morphine, the neurotoxic effects of Tat were completely abolished, since neurons in the Tat and morphine co-exposure group showed no additional losses compared to controls. Naloxone pre-treatment blocked the ability of morphine to exacerbate neuronal losses following Tat exposure (compare Fig. 3a, b). Importantly, naloxone also reversed the unexpected protective effects of morphine in CCR5-deficient glial cultures co-exposed to Tat. The paradoxical effect of morphine to protect against Tat neurotoxicity CCR5-deficient conditions thus appears to be mediated through actions meditated by opioid receptors. These effects were presumed specific for glial loss of CCR5, as cultures with CCR5-deficient neurons, but with CCR5-expressing glia, exhibited levels of neuronal death similar to those seen in wild-type co-cultures 

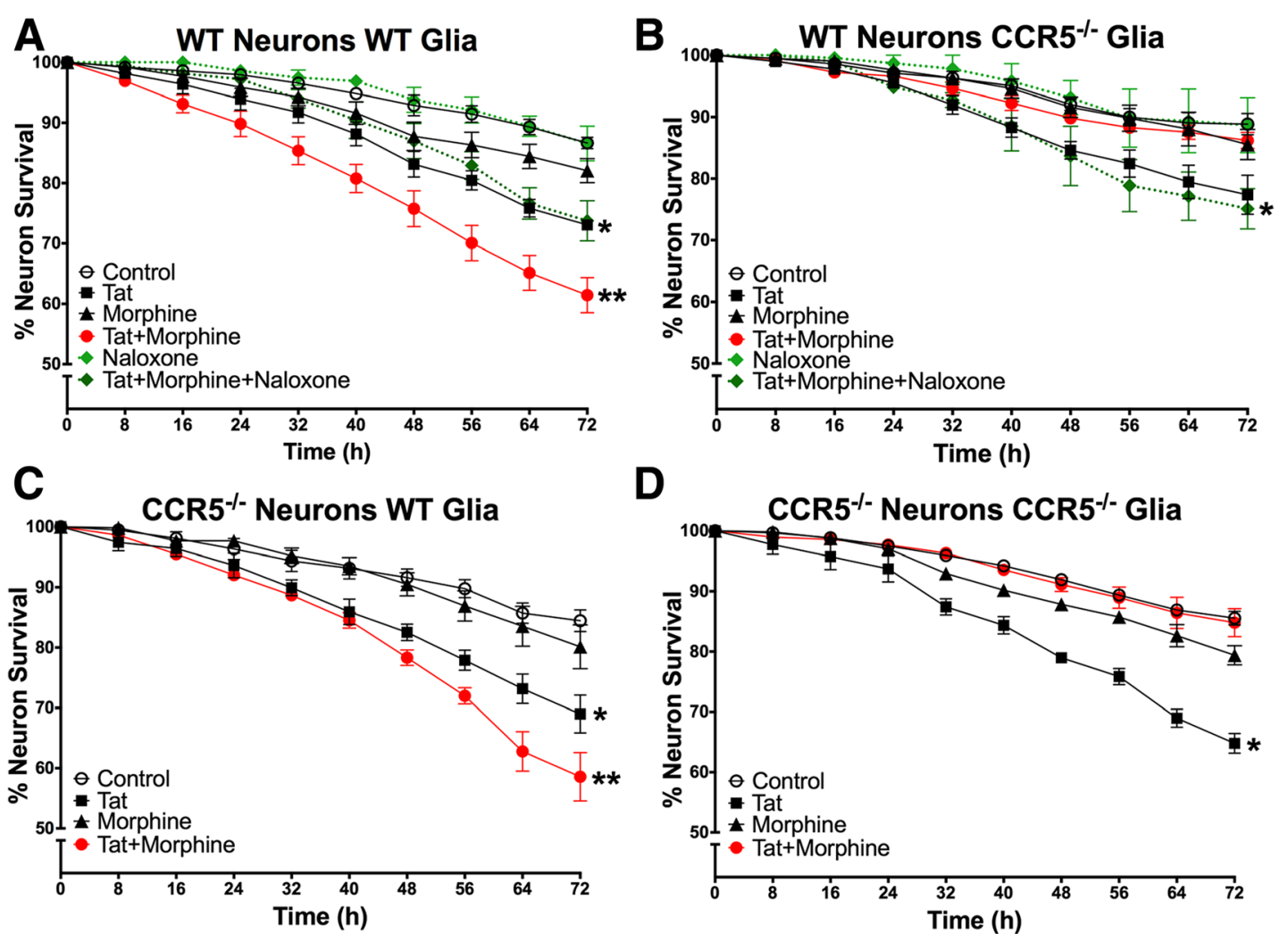

Fig. 3 Neurotoxic effects of HIV-1 Tat and morphine are reversed by loss of glial CCR5. a In C57Bl6/J wild-type co-cultures, Tat is neurotoxic ( ${ }^{*} p=0.001$ vs control), and co-exposure to morphine enhanced Tat-induced toxicity over a 72 -h period ${ }^{* *} p<0.001$ vs control, $p<0.05$ vs Tat). This interaction was blocked by pretreatment with naloxone, a broad-spectrum opioid receptor antagonist. Naloxone or morphine by themselves had no effect on neuronal survival ( $n=4-8)$. b-d To explore the role of CCR5 in mediating neurotoxic interactions between Tat and morphine, co-cultures in which glia, neurons, or both were deficient in CCR5 were established. $\mathbf{b}$ In co-cultures where glia are CCR5-null but neurons are wild-type, exposure to Tat by itself still led to significant neurotoxicity ( ${ }^{*} p<0.001$ vs control); however, the morphine-enhanced neurotoxicity seen in wild-type cultures was eliminated. In fact, morphine co-treatment entirely abolished Tat toxic effects, restoring neuronal survival to control levels. Pre-treatment with naloxone re-established Tat toxicity, suggesting that actions at the $\mu$-opioid receptor mediate this neuroprotection $(n=4-8)$. $\mathbf{c}$ In co-cultures where neurons are CCR5-null but glia are wildtype, the survival curves are similar to wild-type co-cultures $(n=5)$. $\mathbf{d}$ In co-cultures between CCR5-deficient glia and neurons, the survival curves are similar to co-cultures where only glia were CCR5-deficient $(n=5)$. Overall, the results from the CCR5-deficient co-cultures suggest an important role for glial CCR5 in the neurotoxic interactions of HIV-1 Tat and opiates that act at the MOR

exposed to Tat \pm morphine (Fig. 3c). Importantly, there was no effect of morphine alone on neuronal survival in any combination of the co-cultured cells. Lastly, cocultures in which both neurons and glia were CCR5deficient showed survival curves similar to those in which glia alone were CCR5-deficient (Fig. 3d). Overall, these results suggest an important role for CCR5-expressing glia, as well as the importance of CCR5 and MOR interactions, in mediating the neurotoxic interactions of HIV-1 Tat and opiates.

\section{Constitutive CCR5 loss affects neuronal survival differently than short-term CCR5 blockade} Long-term, constitutive knockout of CCR5 might result in compensatory changes during development that alter neuronal sensitivity to Tat or morphine. To explore this hypothesis, we used a paradigm where the length of CCR5 blockade was controlled using the CCR5 antagonist maraviroc (Fig. 4). Here we show that a relatively long-term, 2-week incubation with maraviroc (LT-MVC) mimicked the effects on neuron survival seen in cocultures with CCR5-deficient glia. That is, morphine-Tat interactions that enhance neurotoxicity were negated, and morphine additionally protected completely against Tat neurotoxicity. However, shorter-term exposure to maraviroc, starting immediately before Tat and morphine were co-administered (ST-MVC), had much more limited effects. Short-term maraviroc treatment reduced the interactive effects of Tat and morphine; however, it did not reduce the neurotoxicity of Tat itself irrespective of whether morphine was present. 


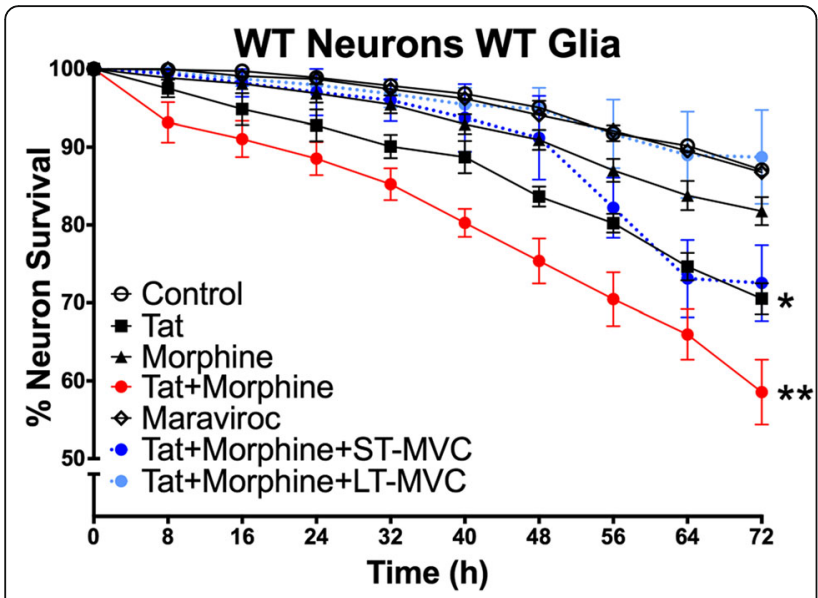

Fig. 4 Constitutive CCR5 loss affects neuron survival differently than short-term CCR5 blockade. Maraviroc was applied to the co-culture to compare the effects of a CCR5 antagonist to a genetic knockout. Maraviroc was applied in two different paradigms that permitted us to manipulate the time period of CCR5 loss. The first was a shortterm pre-treatment immediately before adding Tat and/or morphine (ST-MVC; $n=4$ ); in this paradigm, maraviroc was on the cultures for a period of $72 \mathrm{~h}$, during the time of Tat and morphine treatments. The second was a longer-term exposure starting 3 days after glia were plated and continuing for the entire 2-week duration of the experiment with replacement of the media every $48 \mathrm{~h}(\mathrm{LT}-\mathrm{MVC} ; n=4)$. The Tat + morphine + LT-MVC survival curve matched that of cultures with CCR5deficient glia. The Tat + morphine + ST-MVC eliminated the morphineTat interaction and only showed a trend towards eliminating Tat toxicity $(p=0.08$ vs control). This set of studies suggests that compensatory effects occur over time with CCR5, which dramatically alter morphineTat interaction and neurotoxicity

\section{Maraviroc protects against acute increases in neuronal $\left[\mathrm{Ca}^{2+}\right]_{\mathrm{i}}$}

Disruptions in calcium homeostasis are a common response to neurotoxic signals. As an indicator of how maraviroc affected neuronal function, we performed ratiometric imaging with Fura- 2 to assess changes in the $\left[\mathrm{Ca}^{2+}\right]_{\mathrm{i}}$ level of individual neurons over a 60 -min period of treatment with Tat \pm morphine \pm maraviroc. Tat \pm morphine treatments significantly increased $\left[\mathrm{Ca}^{2+}\right]_{\mathrm{i}}$ by $15 \mathrm{~min}$, and this was maintained for the duration of the trial (Fig. 5). Importantly, even at this early time point, co-exposure to maraviroc blocked the changes, suggesting that reduced CCR5 signaling had the effect of maintaining normal $\left[\mathrm{Ca}^{2+}\right]_{\mathrm{i}}$ levels and stabilizing neuronal function.

\section{BDNF protects against Tat toxicity and HIV-1 Tat and morphine interactions}

BDNF was applied to co-cultures to see if it would promote the survival of striatal neurons co-exposed to Tat + morphine. Co-cultures of wild-type neurons and glia were treated with BDNF concurrently with combined
Tat and morphine for $72 \mathrm{~h}$. Time-lapse analysis demonstrated that exogenous BDNF was partially protective against the neurotoxic effects of Tat alone, which was not the case for CCR5 deficiency. However, similar to CCR5 deficiency, BDNF reversed the combined neurotoxic effects of Tat + morphine (Fig. 6). BDNF alone at this concentration did not increase the survival of neurons in untreated, wild-type cultures; survival of both was over $90 \%$.

\section{Loss of glial CCR5 expression produces a shift in proBDNF/BDNF levels}

Based on our prior studies demonstrating significant but reversible reduction in glial production of mBDNF after exposure to HIV-infected supernatant \pm morphine [48], as well as other studies where HIV-1 gp120 altered BDNF processing [47], we analyzed levels of both mBDNF and its precursor, proBDNF, which binds p75NTR to activate cell death pathways. We also compared changes in their ratios. Wild-type and CCR5deficient glial cultures were treated with Tat (Fig. 7a), morphine (Fig. 7b), or concurrent Tat and morphine (Fig. 7c) and harvested at 6- and 24-h time points for protein analysis. After Tat treatment, mBDNF levels measured by ELISA were unchanged from levels in media in untreated control cultures at both $6 \mathrm{~h}$ and $24 \mathrm{~h}$ (Fig. 7a (i, iv)). Tat by itself significantly reduced proBDNF in wild-type cultures versus control cultures at $6 \mathrm{~h}$, with a strong trend towards reduction in both wild-type and CCR5-deficient cultures at $24 \mathrm{~h}$ (Fig. 7a (ii, v)). Morphine by itself reduced only proBDNF and only in CCR5-deficient cultures (Fig. 7b (ii, v)). The combination of Tat and morphine showed a strong trend to reduce mBDNF in wild-type cultures at $6 \mathrm{~h}$ (Fig. 7c (i)) and was the only treatment to affect mBDNF. The ratio of proBDNF to mBDNF has been used as one index of relative neurotrophic support [47]. CCR5 deficiency strongly reduced this ratio by over twofold at $6 \mathrm{~h}$ in cells treated with Tat and morphine (Fig. 7c (iii)), and the protection of neurons in the CCR5-deficient glial environment may reflect the relative increase in $\mathrm{mBDNF}$. A similar trend noted at $24 \mathrm{~h}$ was noted $(p=0.17)$ (Fig. 7c (vi)). The only other significant change in this ratio was a much smaller, but still significant, decrease in CCR5-deficient cultures treated with Tat (Fig. 7a (vi)).

\section{Discussion}

Mild-to-moderate HAND still occurs in roughly $50 \%$ of HIV-infected individuals who receive typical antiretroviral therapy, in part due to relatively low penetration of cART drugs through the blood-brain barrier but also due to the extended lifespan afforded by long-term 


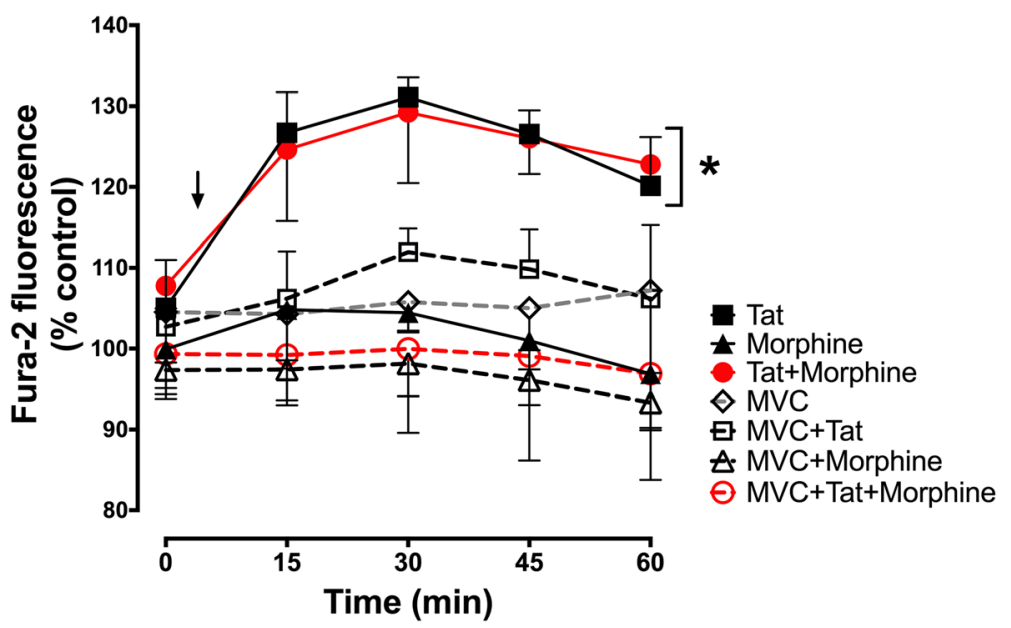

Fig. 5 Maraviroc reduces Tat-mediated increases in $\left[\mathrm{Ca}^{2+}\right]_{\mathrm{i}}$. Intracellular calcium levels were assessed in neuron-glia co-cultures by ratiometric imaging of Fura-2. A series of images were taken every $15 \mathrm{~min}$ for $1 \mathrm{~h}$ to track the response of individual neurons. Initial $\left[\mathrm{Ca}^{2+}\right]_{\mathrm{i}}$ measurements were taken prior to any treatment at the 0-min time point. Tat and/or morphine treatments were applied 10 min prior to the second reading (marked by arrow). There were significant effects for both time $(p=0.001)$ and treatment $(p=0.009)$ when assessed by repeated measures ANOVA. Treatment with Tat or Tat + morphine (marked by asterisk) led to significant increases in $\left[\mathrm{Ca}^{2+}\right]_{\mathrm{i}}$, as indicated by increased F340/F380 ratios. Pre-treatment with maraviroc blocked the Tat + morphine-induced increase ( $p=0.008$; Duncan's post hoc test) as well as the Tat-mediated response $(p=0.054)$. Morphine and maraviroc alone did not significantly alter $\left[\mathrm{Ca}^{2+}\right]_{\mathrm{i}}$. Results are presented as percent of the control F340/F380 ratios for each concurrent time point ( $n=3$ independent experiments)

cART treatment. Even in patients where viral replication is undetectable, the release of toxins such as HIV-1 Tat, an early viral protein required for the transactivation of HIV transcription, can persist. While Tat may have direct excitotoxic effects on neurons, particularly well-

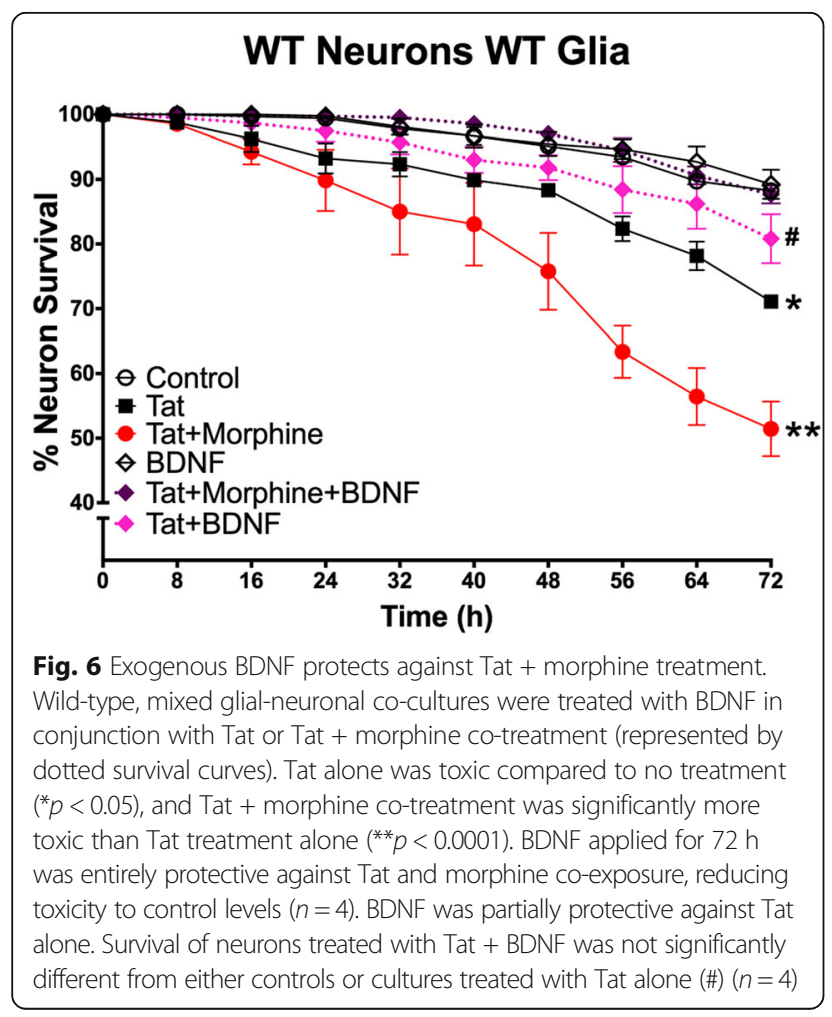

documented in purified neuronal cultures [30, 49], it also fosters an environment of chronic inflammation through effects on astroglia and microglia. This may result in indirect neurotoxicity through the production of reactive oxygen and nitrosative species and via the release of proinflammatory chemokines and cytokines [50-52], triggering a cascade of inflammatory events that is ultimately damaging to neurons. Furthermore, Tat is present in measurable levels circulating in the blood and CSF of HIV patients $[53,54]$, suggesting that it is a clinically relevant surrogate for some aspects of HIV neuropathogenesis, especially in virally suppressed patients.

CCR5 is a chemokine receptor that also functions as a major co-receptor for HIV entry. It is normally expressed at low levels by glia throughout the CNS, but this expression can be upregulated by HIV-1 and by Tat [55]. CCR 5 expression can also be upregulated in an additive or interactive manner with co-exposure to Tat and the preferential MOR agonist morphine [56]. We have been interested in understanding the role of the CCL5-CCR5 axis in mediating HIV and Tat-induced inflammation and neurotoxicity, with a special interest in whether moderating this chemokine system might be useful in reducing neurotoxic interactions between HIV-1 Tat and opiate exposure. We showed that intrastriatal delivery of Tat caused a local inflammation, characterized by astroglial expression of CCL2 (MCP-1) and 3-nitrotyrosine expression in microglia that was exacerbated by co-administering timerelease, subcutaneous morphine pellet implants. Microglial 3-nitrotyrosine and astroglial expression of CCL2 

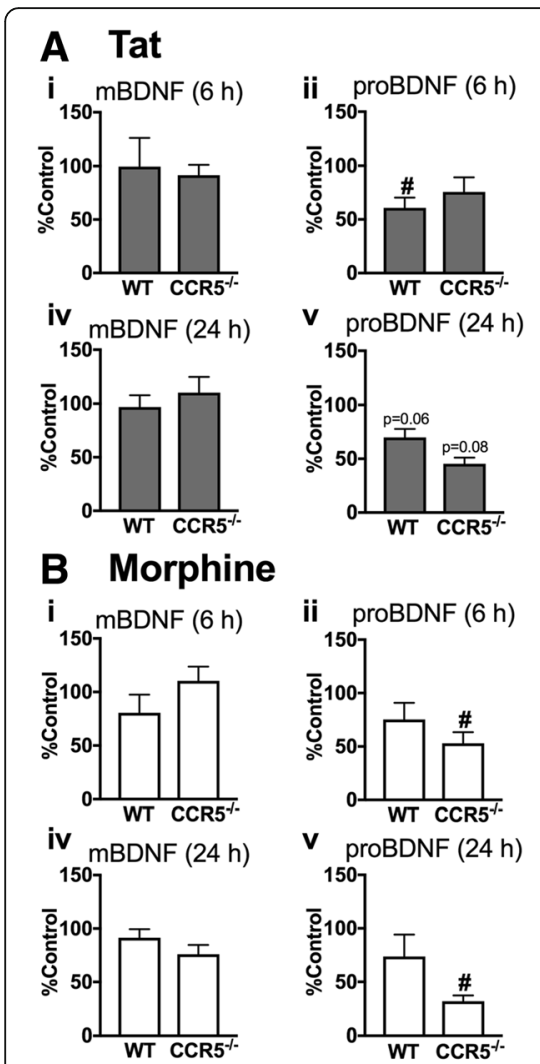

iii

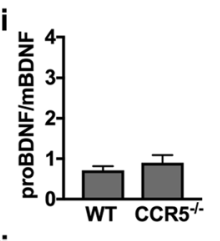

vi

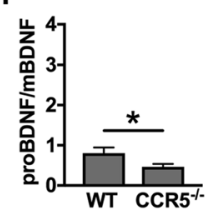

ii $\operatorname{proBDNF}(6 \mathrm{~h})$

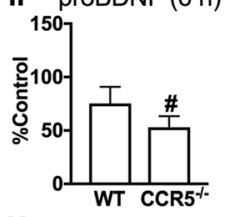

v $\operatorname{proBDNF}(24 \mathrm{~h})$

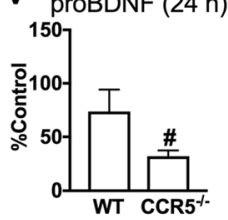

C Tat + Morphine
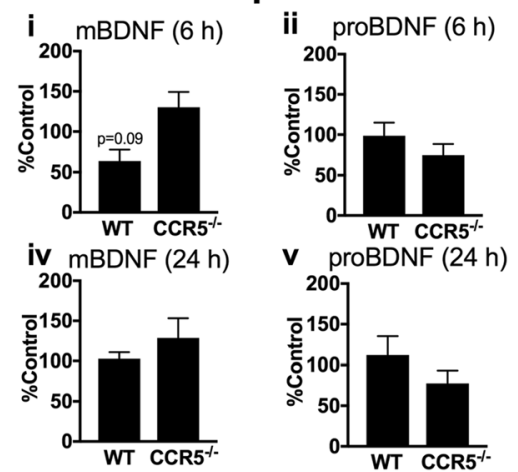

iii

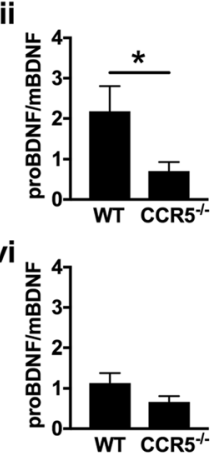

Fig. 7 Loss of glial CCR5 expression produces a shift in proBDNF/mBDNF levels. mBDNF and proBDNF levels were analyzed in conditioned media from wild-type or CCR5-deficient glia treated with Tat and/or morphine after 6 and $24 \mathrm{~h}$ to determine if the levels of proBDNF and mBDNF and their ratios were altered $(n=7-8)$. a Tat significantly reduced proBDNF in wild-type cultures compared to untreated control levels at $6 \mathrm{~h}$ (ii) with similar trends in both genotypes at $24 \mathrm{~h}(\mathrm{v})$. The ratio of proBDNF/mBDNF was significantly higher in wild-type cells at $24 \mathrm{~h}$, suggesting reduced neuronal support (vi). b Morphine significantly decreased proBDNF in CCR5-deficient glia at both 6 and $24 \mathrm{~h}$ compared to control levels (ii, v). These decreases in proBDNF did not significantly alter the proBDNF/ mBDNF ratios (iii, vi). c Tat + morphine treatment did not significantly alter mBDNF and proBDNF levels in glia of either genotype, although there was a strong trend to decrease mBDNF in wild-type cultures at $6 \mathrm{~h}$ (i). Nevertheless the treatment very significantly decreased the proBDNF/ mBDNF ratio at $6 \mathrm{~h}$ (iii), suggesting enhanced protection with CCR5 deficiency. A slight trend towards this shift continued at $24 \mathrm{~h}$ (vi; $p=0.17$ ). $\# p<0.05$ vs control; ${ }^{*} p<0.05$ for all figures were not seen in a CCL5 (RANTES)-deficient mouse, strongly implicating CCL5-to-CCR5 signaling in the amplification of astroglial CCL2 production and resultant macrophage/microglial activation and recruitment [45]. In a related study, we also showed that pretreating Tat-inducible transgenic mice with maraviroc attenuated the withdrawal-mediated increase in levels of many of the cytokines that occurred in mice co-exposed to Tat and morphine and restored antinociceptive properties of morphine that were attenuated by Tat [57]. CCR5 loss is also protective against other HIV proteins, including gp120 [58], as assessed by reduced neuronal damage and microglial activation.

The present studies used both genetic (glia and neurons derived from a constitutive, CCR5-deficient mouse) and pharmacologic (CCR5 blocker maraviroc) approaches to demonstrate that CCR5 is directly involved in HIV neuropathogenic mechanisms irrespective of viral titers. That CCR5 plays a role in the inflammatory processes associated with many disease states, such as cerebral ischemia and reperfusion injury, and neuropathic pain is well-established $[59,60]$. In HIV, the role of CCR5 in neurologic outcomes is more difficult to assign since CCR5 is a major co-factor for the infection process. A naturally occurring, 32 base-pair deletion in the CCR5 gene produces a nonfunctional protein, effectively rendering a knockout of the receptor. HIV+ individuals who possess one copy of this mutation show slower progression to AIDS and a reduced occurrence of HAND than those without the mutation [36, 37]. Studies in which maraviroc supplemented the antiretroviral therapy regimen in virally suppressed patients led to improvements in cognition [41, 61]. However, due to the role of CCR5 as a co-receptor for HIV entry, it is unclear if the reduced prevalence of HAND in this population is due to decreased inflammation or decreased progression of infection. In this study, we isolated the inflammatory effects of HIV-1 Tat without the confounding effects of viral infection and replication in monocytes and microglia. Since our paradigm is non-infectious, the findings establish that blocking CCR5 activity can significantly improve neuronal outcomes by mechanisms not involving reduced HIV infection.

As we hypothesized, when CCR5 was deleted from glia in mixed glial cultures, co-cultured neurons were protected against the enhanced degree of toxicity resulting from co-exposure to Tat and morphine. Surprisingly, when CCR5 was absent from glia, morphine appeared to entirely protect co-cultured neurons from the effects of Tat (Fig. 3b). These findings were further explored and confirmed in an alternative, pharmacological approach utilizing maraviroc to control the length of CCR5 blockade. When maraviroc was given to more mature co-cultures concurrent with Tat \pm morphine treatments 
for $72 \mathrm{~h}$, protection was seen against the interactive effects of Tat and morphine co-exposure. In co-cultures incubated with maraviroc for their entire developmental period in vitro, to mimic a constitutive knockout, neurons were additionally protected from Tat-induced toxicity when morphine was present (Fig. 4). Maraviroc may thus afford additional neuroprotection to individuals exposed to opioids, depending on timing and duration of maraviroc therapy. Notably, maraviroc blocked the increase in neuronal $\left[\mathrm{Ca}^{2+}\right]_{\mathrm{i}}$ seen at acute time points after exposure to Tat \pm morphine (Fig. 5), suggesting that early events leading to neuronal dysfunction may be CCR5-dependent and reversible. Naloxone pretreatment revealed that both the predicted and unexpected protective effects of morphine were mediated by opioid receptors.

We explored a potential mechanism for the aforementioned protective effects against both Tat and Tat + morphine. BDNF, a neurotrophin that modulates development and survival of young neurons and is important in establishing and maintaining normal synaptic connectivity, has surfaced as a potential therapeutic target in HAND. Both microglia and astrocytes can be a major source of released BDNF [62,63]. The mature form of BDNF (mBDNF) preferentially binds TrkB, through which it initiates PI3K and MAPK signaling pathways in neurons, as well as NF- $\mathrm{kB}$-mediated activation of transcription factors $[64,65]$. proBDNF binds the alternative p75NTR to initiate pro-apoptotic cascades [66]. Levels of mBDNF are reportedly reduced in HIV+ individuals and also modulated by drugs of abuse $[47,67,68]$. For example, morphine exposures in vivo appear to increase the extracellular protease tissue plasminogen activator, thus increasing cleavage of proBDNF to mBDNF. Withdrawal from morphine had the opposite effect [69]. Intracellular conversion of proBDNF to mBDNF in neurons is reduced by the HIV surface envelope protein gp120, which reduces levels of the intracellular protease furin [47]. Exogenous mBDNF can rescue neurons exposed to gp120 both in vivo and in vitro [70,71], likely involving downregulation of CXCR4. In a prior study involving glia exposed to HIV-infective supernatant \pm morphine, mBDNF levels, but not glial-derived neurotrophic factor (GDNF) levels, were significantly decreased. This reduction was reversed upon removal of HIV treatment [48]. The relatively higher proBDNF/ mBDNF ratio measured in the medium of wild-type versus CCR5-null glial cultures exposed to Tat and morphine (Fig. 7c (iii)) is in line with the outcomes above since neurons co-cultured with CCR5-null glia were protected. We measured significant differences in proBDNF/mBDNF ratios at $6 \mathrm{~h}$ with trends at $24 \mathrm{~h}$. These time points reflect prior studies that have demonstrated transient increases in BDNF mRNA and protein levels. For instance, response to cortical injury in rats involves an increase in BDNF mRNA from $1 \mathrm{~h}$ that begins to decline after $24 \mathrm{~h}[72,73]$. gp120 also leads to early changes in BDNF and proBDNF release from cerebellar or cortical neurons, from $1 \mathrm{~h}$ post-treatment [47]. As demonstrated by the persistently high percentage of neuronal survival in BDNF-treated co-cultures (Fig. 4), these rapid, transient neuroprotective signals may result in long-lasting effects even in the face of a complex milieu of secondary and tertiary factors by $72 \mathrm{~h}$ of treatment exposure. Activation of p75NTR, for instance, in multiple cell types has elucidated a role in immune response regulation. Injury to retinal ganglion neurons leads to the upregulation of p75NTR of nearby Müller glial cells, which can activate downstream cytokine production that is thought to eventually lead to the damage and demise of bystander neurons [74]. Our findings are further supported in other models of neuronal injury such as cerebral ischemia, in which the loss of CCR5 reduces long-term inflammatory injury, potentially through increases in BDNF levels [60, 75]. However, while we demonstrated that Tat and/or morphine treatment led to specific changes in $\mathrm{mBDNF}$ and proBDNF levels, shifts in p75NTR and TrkB levels may add a degree of complexity in determining the fate of the neurons, as receptor expression is responsive to injury in a time- and cell-dependent manner [76-78].

Opiates and HIV have historically been interlinked epidemics, and injection drug use carries an increased risk of contracting HIV. Moreover, opiates are used to manage HIV-related pain syndromes, which may impact HAND symptoms in virally suppressed individuals. Cooperative effects between HIV and opiates that increase CNS inflammation are well-documented, and many involve the HIV co-receptor CCR5. For example, opiates modulate CCR5 expression in a number of CNS and immune cells, including microglia [56], astrocytes [79], and peripheral monocytes [43], and can thereby increase rates of HIV infection as well as pro-inflammatory products and immune cell recruitment. The analgesic properties of MOR activation are also reduced when there is an abundance of CCR5 ligands [80]. MOR function is also altered by Tat exposure, which lowers morphine efficacy through decreased G-protein activation [81]. Reduced MOR signaling would tend to increase the amounts of opiates used by HIV-infected individuals for effective analgesia or for illicit effects.

In earlier studies, wild-type neurons co-cultured with MOR-deficient glia were completely protected against the exaggerated neurotoxic effects of co-exposure to Tat + morphine. These result were consistent with findings that the selective MOR antagonist $\beta$-funaltrexamine prevented morphine from exacerbating Tat-induced increases in proinflammatory cytokine transcripts in 
astroglia [27]. Surprisingly, morphine also afforded neuroprotection against Tat [30]. Given that the present results show strikingly similar protective effects in the absence of glial CCR5 (Fig. 3b), a possible interaction between CCR5 and MOR signaling that modulates neuroprotection seems likely. Some interactions between opiates and CCR5 are likely to involve the heterologous interactions that can occur between Gprotein-coupled receptors (GPCRs) and that have been shown for MOR and CCR5 [82, 83]. Heterologous desensitization may explain a reduced chemotactic effect of CCR5 by pretreatment with MOR agonists [80]. Recently, synthetic, bivalent ligands composed of maraviroc and naltrexone that target the proposed CCR5-MOR heteromers/oligomers have shown that such interactions may occur in a cell type-specific manner [84-86]. The inability to form MOR-CCR5 heterodimers in CCR5-null (or MOR-null) glia may alter the cellular response to concurrent morphine exposure, contributing to neuroprotection. Although such a response might additionally involve contributions from $\mathrm{K}$-(KOR) or $\delta$-(DOR) opioid receptors, morphine has lower affinity at KOR or DOR (than MOR). Prior studies also indicate that MOR is largely responsible for the morphine and Tat-induced inflammation and bystander neurotoxicity that is mediated by glia $[28,30]$.

This study establishes a role of glial CCR5, unrelated to infective processes, in mediating neurotoxicity due to HIV-1 Tat and the interactive effects of Tat and morphine. The differential toxic versus protective effects of morphine in the presence or absence of CCR5 hint at complex relationships that may involve heterologous interactions between CCR5 and MOR. Other results infer a role for BDNF, and perhaps an altered balance between proBDNF and mBDNF levels, in some aspects of the protection. These studies are particularly pertinent to HIV+ individuals who are virally suppressed, yet still develop mild neurocognitive deficits via ongoing, low levels of neuroinflammation in the CNS that involve CCR5 activation.

\section{Conclusion}

HIV antiretroviral therapy has been successful in limiting AIDS-related complications, but neurocognitive deficits due to the inflammation driven by early CNS viral penetration persist in up to $50 \%$ of HIV-infected individuals. Opiate exposure, which is common in the HIV+ population, worsens the severity of HAND. The cellular mechanism(s) that exacerbate inflammation and CNS disease remain largely unexplained. We tested the hypothesis that the CCL5-CCR5 axis plays a pivotal role in opiate exacerbation of HIV deficits using both genetic and pharmacological approaches. Loss of glial, but not neuronal, CCR5 protected striatal neurons from HIV-1
Tat and morphine co-exposure. Importantly, loss of CCR5 not only blocked the interactive effects of Tat and morphine, but also reversed the Tat toxicity seen in the cultures as long as morphine was present. These findings were confirmed with both long- and short-term exposure to the CCR5 antagonist maraviroc. We measured a shift in the ratio of proBDNF/mBDNF released from CCR5-deficient glia that favored neuroprotection, and exogenous BDNF protected neurons from HIV-1 Tat and morphine exposure in a manner that mirrored the effects of CCR5 deficiency. Our findings suggest that CCR5 is involved in processes that impact neuronal survival and function unrelated to its important role in HIV infection, at least partly by altering the balance between proBDNF and mBDNF levels. The differential toxicity of morphine/opioids in the presence or absence of CCR5 also hints at complex relationships between CCR5 and MOR that may involve heterologous interactions. Our findings are pertinent in terms of understanding and treating HIV+ individuals who develop neurocognitive deficits even though their peripheral viremia is wellcontrolled.

\section{Abbreviations \\ $\left[\mathrm{Ca}^{2+}\right]_{\mathrm{i}}$ : Intracellular calcium concentration; ANOVA: Analysis of variance; BDNF: Brain-derived neurotrophic factor; CART: Combined antiretroviral therapy; CCL2: C-C chemokine ligand 2; CCR5: C-C chemokine receptor 5; CNS: Central nervous system; DOR: $\delta$-opioid receptor; ELISA: Enzyme-linked immunosorbent assay; GDNF: Glial-derived neurotrophic factor; Gp120: Glycoprotein 120; GPCR: G-protein-coupled receptor; HAND: HIV-associated neurocognitive disorders; HIV: Human immunodeficiency virus; KOR: K-opioid receptor; MAPK: Mitogen-activated protein kinase; MOR: $\mu$-opioid receptor; NF- kB: Nuclear factor kappa-light-chain-enhancer of activated B cells; NTR: Neurotrophin receptor; PI3K: Phosphoinositide 3-kinase; ROI: Region of interest; Tat: HIV-1 transactivator of transcription; tPA: Tissue plasminogen activator; \\ TrkB: Tyrosine receptor kinase $B$}

\section{Funding}

This work was supported by the NIH (R01 DA034231 to PEK and KFH, F30 DA044875 to SK, K02DA027374 to KFH). The sponsors were not involved in the design of the study; the collection, analysis, and interpretation of the data, the writing of the manuscript; nor the decision to submit for publication.

\section{Availability of data and materials}

The datasets used and/or analyzed during the current study are available from the corresponding author on reasonable request.

\section{Authors' contributions}

PEK and KFH designed the research project and PEK supervised the work. SK conducted all experiments presented in the main body of the text and contributed to the design of the study. EMP conducted preliminary studies and contributed to manuscript revisions. YKH, SZ, and VDM were involved in developing the immunoblot/ELISA, time-lapse imaging/analysis, and intracellular calcium assessment methods, respectively, and also contributed to manuscript revisions. SK and PEK wrote the manuscript. PEK, KFH, and SK secured funding for this project. All authors read and approved the final manuscript.

\section{Ethics approval}

Experiments were conducted in compliance with procedures reviewed and approved by the Virginia Commonwealth University Institutional Animal Care and Use Committee. 


\section{Consent for publication}

Not applicable

\section{Competing interests}

The authors declare that they have no competing interests.

\section{Publisher's Note}

Springer Nature remains neutral with regard to jurisdictional claims in published maps and institutional affiliations.

\section{Author details}

'Department of Anatomy and Neurobiology, Virginia Commonwealth University School of Medicine, 1217 E. Marshall St, Richmond, VA 23298-0709, USA. ${ }^{2}$ Department of Pharmacology and Toxicology, Virginia Commonwealth University, Richmond, VA 23298, USA. ${ }^{3}$ Institute for Drug and Alcohol Studies, Virginia Commonwealth University, Richmond, VA 23298, USA. ${ }^{4}$ Present Address: BioLegend, Inc., 210 Rustcraft Rd., Dedham, MA 02026, USA.

\section{Received: 21 May 2018 Accepted: 19 September 2018}

\section{Published online: 10 October 2018}

\section{References}

1. UNAIDS. http://www.unaids.org/en/resources/fact-sheet. Accessed on 10 Jan 2018.

2. Yazdanian M. Blood-brain barrier properties of human immunodeficiency virus antiretrovirals. J Pharm Sci. 1999;88:950-4.

3. Powderly WG. Current approaches to treatment for HIV-1 infection. J NeuroOncol. 2000;6(Suppl 1):S8-s13.

4. Resnick L, Berger JR, Shapshak P, Tourtellotte WW. Early penetration of the blood-brain-barrier by HIV. Neurology. 1988;38:9-14.

5. Sturdevant CB, Joseph SB, Schnell G, Price RW, Swanstrom R, Spudich S. Compartmentalized replication of R5 T cell-tropic HIV-1 in the central nervous system early in the course of infection. PLoS Pathog. 2015; 11:e1004720.

6. Xiao Q, Li J, Yu Q, Bao R, Liu J, Liu H, Zhou L, Xian Q, Wang Y, Cheng-Mayer $C$, et al. Distinct compartmentalization in the CNS of SHIVKU-1-infected Chinese rhesus macaque is associated with severe neuropathology. J Acquir Immune Defic Syndr. 2015;70:e168-71.

7. Bednar MM, Sturdevant CB, Tompkins LA, Arrildt KT, Dukhovlinova E, Kincer LP, Swanstrom R. Compartmentalization, viral evolution, and viral latency of HIV in the CNS. Curr HIV/AIDS Rep. 2015;12:262-71.

8. Heaton RK, Clifford DB, Franklin DR Jr, Woods SP, Ake C, Vaida F, Ellis RJ, Letendre SL, Marcotte TD, Atkinson JH, et al. HIV-associated neurocognitive disorders persist in the era of potent antiretroviral therapy: CHARTER study. Neurology. 2010;75:2087-96.

9. Maschke M, Kastrup O, Esser S, Ross B, Hengge U, Hufnagel A. Incidence and prevalence of neurological disorders associated with HIV since the introduction of highly active antiretroviral therapy (HAART). J Neurol Neurosurg Psychiatry. 2000;69:376-80.

10. Sacktor N, McDermott MP, Marder K, Schifitto G, Selnes OA, McArthur JC, Stern Y, Albert S, Palumbo D, Kieburtz K, et al. HIV-associated cognitive impairment before and after the advent of combination therapy. J NeuroOncol. 2002;8:136-42.

11. Antinori A, Arendt G, Becker JT, Brew BJ, Byrd DA, Cherner M, Clifford DB, Cinque P, Epstein LG, Goodkin K, et al. Updated research nosology for HIVassociated neurocognitive disorders. Neurology. 2007;69:1789-99.

12. Bell JE. An update on the neuropathology of HIV in the HAART era. Histopathology. 2004:45:549-59.

13. Everall I, Vaida F, Khanlou N, Lazzaretto D, Achim C, Letendre S, Moore D, Ellis R, Cherner M, Gelman B, et al. Cliniconeuropathologic correlates of human immunodeficiency virus in the era of antiretroviral therapy. J NeuroOncol. 2009;15:360-70

14. An SF, Groves M, Giometto B, Beckett AA, Scaravilli F. Detection and localisation of HIV-1 DNA and RNA in fixed adult AIDS brain by polymerase chain reaction/in situ hybridisation technique. Acta Neuropathol. 1999;98:481-7

15. Takahashi K, Wesselingh SL, Griffin DE, McArthur JC, Johnson RT, Glass JD. Localization of HIV-1 in human brain using polymerase chain reaction/in situ hybridization and immunocytochemistry. Ann Neurol. 1996:39:705-11.
16. Wiley CA, Schrier RD, Nelson JA, Lampert PW, Oldstone MB. Cellular localization of human immunodeficiency virus infection within the brains of acquired immune deficiency syndrome patients. Proc Natl Acad Sci U S A. 1986:83:7089-93.

17. Cosenza MA, Zhao ML, Si Q, Lee SC. Human brain parenchymal microglia express CD14 and CD45 and are productively infected by HIV-1 in HIV-1 encephalitis. Brain Pathol. 2002;12:442-55.

18. Kramer-Hammerle S, Rothenaigner I, Wolff H, Bell JE, Brack-Werner R. Cells of the central nervous system as targets and reservoirs of the human immunodeficiency virus. Virus Res. 2005;111:194-213.

19. Williams KC, Hickey WF. Central nervous system damage, monocytes and macrophages, and neurological disorders in AIDS. Annu Rev Neurosci. 2002 25:537-62.

20. Churchill MJ, Wesselingh SL, Cowley D, Pardo CA, McArthur JC, Brew BJ, Gorry PR. Extensive astrocyte infection is prominent in human immunodeficiency virus-associated dementia. Ann Neurol. 2009;66:253-8.

21. Bagasra O, Lavi E, Bobroski L, Khalili K, Pestaner JP, Tawadros R, Pomerantz RJ. Cellular reservoirs of HIV-1 in the central nervous system of infected individuals: identification by the combination of in situ polymerase chain reaction and immunohistochemistry. AIDS. 1996;10:573-85.

22. Anthony IC, Arango JC, Stephens B, Simmonds P, Bell JE. The effects of illicit drugs on the HIV infected brain. Front Biosci. 2008;13:1294-307.

23. Byrd DA, Fellows RP, Morgello S, Franklin D, Heaton RK, Deutsch R, Atkinson $J \mathrm{H}$, Clifford DB, Collier AC, Marra CM, et al. Neurocognitive impact of substance use in HIV infection. J Acquir Immune Defic Syndr. 2011;58:154-62.

24. Martin-Thormeyer EM, Paul RH. Drug abuse and hepatitis C infection as comorbid features of HIV associated neurocognitive disorder: neurocognitive and neuroimaging features. Neuropsychol Rev. 2009;19: 215-31.

25. Bell JE, Arango JC, Anthony IC. Neurobiology of multiple insults: HIV-1associated brain disorders in those who use illicit drugs. J Neurolmmune Pharmacol. 2006:1:182-91.

26. Rogers TJ, Peterson PK. Opioid G protein-coupled receptors: signals at the crossroads of inflammation. Trends Immunol. 2003:24:116-21.

27. El-Hage N, Gurwell JA, Singh IN, Knapp PE, Nath A, Hauser KF. Synergistic increases in intracellular $\mathrm{Ca}^{2+}$, and the release of MCP-1, RANTES, and IL-6 by astrocytes treated with opiates and HIV-1 Tat. Glia. 2005;50:91-106.

28. El-Hage N, Wu G, Wang J, Ambati J, Knapp PE, Reed JL, Bruce-Keller AJ, Hauser KF. HIV-1 Tat and opiate-induced changes in astrocytes promote chemotaxis of microglia through the expression of MCP-1 and alternative chemokines. Glia. 2006:53:132-46.

29. El-Hage N, Bruce-Keller AJ, Yakovleva T, Bazov I, Bakalkin G, Knapp PE, Hauser KF. Morphine exacerbates HIV-1 Tat-induced cytokine production in astrocytes through convergent effects on $\left[\mathrm{Ca}^{2+}\right]_{\mathrm{i}}, \mathrm{NF}-\mathrm{KB}$ trafficking and transcription. PLoS One. 2008:3:e4093.

30. Zou S, Fitting S, Hahn YK, Welch SP, El-Hage N, Hauser KF, Knapp PE. Morphine potentiates neurodegenerative effects of HIV-1 Tat through actions at $\mu$-opioid receptor-expressing glia. Brain. 2011;134:3616-31.

31. Sorce $\mathrm{S}$, Myburgh $\mathrm{R}$, Krause $\mathrm{KH}$. The chemokine receptor CCR5 in the central nervous system. Prog Neurobiol. 2011;93:297-311.

32. Kelder W, McArthur JC, Nance-Sproson T, McClernon D, Griffin DE. $\beta$ chemokines MCP-1 and RANTES are selectively increased in cerebrospinal fluid of patients with human immunodeficiency virus-associated dementia. Ann Neurol. 1998:44:831-5.

33. McManus CM, Weidenheim K, Woodman SE, Nunez J, Hesselgesser J, Nath A, Berman JW. Chemokine and chemokine-receptor expression in human glial elements: induction by the HIV protein, Tat, and chemokine autoregulation. Am J Pathol. 2000;156:1441-53.

34. Martin-Blondel G, Brassat D, Bauer J, Lassmann H, Liblau RS. CCR5 blockade for neuroinflammatory diseases--beyond control of HIV. Nat Rev Neurol. 2016;12:95-105

35. Dragic T, Litwin V, Allaway GP, Martin SR, Huang Y, Nagashima KA, Cayanan C, Maddon PJ, Koup RA, Moore JP, Paxton WA. HIV-1 entry into CD4+ cells is mediated by the chemokine receptor CC-CKR-5. Nature. 1996;381:667-73.

36. Dean M, Carrington M, Winkler C, Huttley GA, Smith MW, Allikmets $R$, Goedert JJ, Buchbinder SP, Vittinghoff E, Gomperts E, et al. Genetic restriction of HIV-1 infection and progression to AIDS by a deletion allele of the CKR5 structural gene. Hemophilia growth and development study, multicenter AIDS cohort study, multicenter hemophilia cohort study, San Francisco City cohort, ALIVE study. Science. 1996;273:1856-62. 
37. Ioannidis JP, Rosenberg PS, Goedert JJ, Ashton $L J$, Benfield TL, Buchbinder SP, Coutinho RA, Eugen-Olsen J, Gallart T, Katzenstein TL, et al. Effects of CCR5- $\triangle 32$, CCR2-64I, and SDF-1 3'A alleles on HIV-1 disease progression: an international meta-analysis of individual-patient data. Ann Intern Med. 2001; 135:782-95.

38. Levine AJ, Singer EJ, Shapshak $P$. The role of host genetics in the susceptibility for HIV-associated neurocognitive disorders. AIDS Behav. 2009;13:118-32.

39. Llibre JM, Rivero A, Rojas JF, Garcia Del Toro M, Herrero C, Arroyo D, Pineda JA, Pasquau J, Masia M, Crespo M, et al. Safety, efficacy and indications of prescription of maraviroc in clinical practice: factors associated with clinical outcomes. Antivir Res. 2015;120:79-84.

40. Kelly KM, Beck SE, Metcalf Pate KA, Queen SE, Dorsey JL, Adams RJ, Avery LB, Hubbard W, Tarwater PM, Mankowski JL. Neuroprotective maraviroc monotherapy in simian immunodeficiency virus-infected macaques: reduced replicating and latent SIV in the brain. AIDS. 2013;27:F21-8.

41. Gates TM, Cysique LA, Siefried KJ, Chaganti J, Moffat KJ, Brew BJ. Maravirocintensified combined antiretroviral therapy improves cognition in virally suppressed HIV-associated neurocognitive disorder. AIDS. 2016;30:591-600.

42. Ndhlovu LC, Umaki T, Chew GM, Chow DC, Agsalda M, Kallianpur KJ, Paul R, Zhang G, Ho E, Hanks N, et al. Treatment intensification with maraviroc (CCR5 antagonist) leads to declines in CD16-expressing monocytes in CART-suppressed chronic HIV-infected subjects and is associated with improvements in neurocognitive test performance: implications for HIV-associated neurocognitive disease (HAND). J NeuroOncol. 2014;20:571-82.

43. Guo CJ, Li Y, Tian S, Wang X, Douglas SD, Ho WZ. Morphine enhances HIV infection of human blood mononuclear phagocytes through modulation of $\beta$-chemokines and CCR5 receptor. J Investig Med. 2002;50:435-42.

44. Miyagi T, Chuang LF, Doi RH, Carlos MP, Torres JV, Chuang RY. Morphine induces gene expression of CCR5 in human CEMx174 lymphocytes. J Biol Chem. 2000;275:31305-10.

45. El-Hage N, Bruce-Keller AJ, Knapp PE, Hauser KF. CCL5/RANTES gene deletion attenuates opioid-induced increases in glial CCL2/MCP-1 immunoreactivity and activation in HIV-1 Tat-exposed mice. J Neurolmmune Pharmacol. 2008;3:275-85.

46. Avdoshina $\vee$, Garzino-Demo A, Bachis A, Monaco MC, Maki PM, Tractenberg RE, Liu C, Young MA, Mocchetti I. HIV-1 decreases the levels of neurotrophins in human lymphocytes. AIDS. 2011;25:1126-8.

47. Bachis A, Avdoshina V, Zecca L, Parsadanian M, Mocchetti I. Human immunodeficiency virus type 1 alters brain-derived neurotrophic factor processing in neurons. J Neurosci. 2012;32:9477-84.

48. Masvekar RR, El-Hage N, Hauser KF, Knapp PE. Morphine enhances HIV1SF162-mediated neuron death and delays recovery of injured neurites. PLoS One. 2014;9:e100196.

49. Fitting S, Knapp PE, Zou S, Marks WD, Bowers MS, Akbarali HI, Hauser KF. Interactive HIV-1 Tat and morphine-induced synaptodendritic injury is triggered through focal disruptions in $\mathrm{Na}^{+}$influx, mitochondrial instability, and $\mathrm{Ca}^{2+}$ overload. J Neurosci. 2014;34:12850-64.

50. Nath A, Conant K, Chen P, Scott C, Major EO. Transient exposure to HIV-1 Tat protein results in cytokine production in macrophages and astrocytes. A hit and run phenomenon. J Biol Chem. 1999;274:17098-102.

51. Kruman II, Nath A, Mattson MP. HIV-1 protein Tat induces apoptosis of hippocampal neurons by a mechanism involving caspase activation, calcium overload, and oxidative stress. Exp Neurol. 1998;154:276-88.

52. Bruce-Keller AJ, Turchan-Cholewo J, Smart EJ, Geurin T, Chauhan A, Reid R, Xu R, Nath A, Knapp PE, Hauser KF. Morphine causes rapid increases in glial activation and neuronal injury in the striatum of inducible HIV-1 Tat transgenic mice. Glia. 2008;56:1414-27.

53. Wiley CA, Baldwin M, Achim CL. Expression of HIV regulatory and structural mRNA in the central nervous system. AIDS. 1996;10:843-7.

54. Weiss JM, Nath A, Major EO, Berman JW. HIV-1 Tat induces monocyte chemoattractant protein-1-mediated monocyte transmigration across a model of the human blood-brain barrier and up-regulates CCR5 expression on human monocytes. J Immunol. 1999;163:2953-9.

55. Ostrowski MA, Justement SJ, Catanzaro A, Hallahan CA, Ehler LA, Mizell SB, Kumar PN, Mican JA, Chun TW, Fauci AS. Expression of chemokine receptors CXCR4 and CCR5 in HIV-1-infected and uninfected individuals. J Immunol. 1998;161:3195-201.

56. Bokhari SM, Yao H, Bethel-Brown C, Fuwang P, Williams R, Dhillon NK, Hegde R, Kumar A, Buch SJ. Morphine enhances Tat-induced activation in murine microglia. J Neuro-Oncol. 2009;15:219-28.
57. Gonek M, McLane VD, Stevens DL, Lippold K, Akbarali HI, Knapp PE, Dewey WL, Hauser KF, Paris JJ. CCR5 mediates HIV-1 Tat-induced neuroinflammation and influences morphine tolerance, dependence, and reward. Brain Behav Immun. 2018;69:124-38.

58. Maung R, Hoefer MM, Sanchez AB, Sejbuk NE, Medders KE, Desai MK, Catalan IC, Dowling CC, de Rozieres CM, Garden GA, et al. CCR5 knockout prevents neuronal injury and behavioral impairment induced in a transgenic mouse model by a CXCR4-using HIV-1 glycoprotein 120. J Immunol. 2014;193:1895-910.

59. Sun S, Chen D, Lin F, Chen M, Yu H, Hou L, Li C. Role of interleukin-4, the chemokine CCL3 and its receptor CCR5 in neuropathic pain. Mol Immunol. 2016;77:184-92.

60. Victoria ECG, de Brito Toscano EC, de Sousa Cardoso AC, da Silva DG, de Miranda AS, da Silva Barcelos L, Sugimoto MA, Sousa LP, de Assis Lima IV, de Oliveira ACP, et al. Knockdown of C-C chemokine receptor 5 (CCR5) is protective against cerebral ischemia and reperfusion injury. Curr Neurovasc Res. 2017;14:125-31.

61. Barber TJ, Imaz A, Boffito M, Niubo J, Pozniak A, Fortuny R, Alonso J, Davies N, Mandalia S, Podzamczer D, Gazzard B. CSF inflammatory markers and neurocognitive function after addition of maraviroc to monotherapy darunavir/ritonavir in stable HIV patients: the CINAMMON study. J Neuro-Oncol. 2018;24:98-105.

62. Parkhurst CN, Yang G, Ninan I, Savas JN, Yates JR 3rd, Lafaille JJ, Hempstead BL, Littman DR, Gan WB. Microglia promote learning-dependent synapse formation through brain-derived neurotrophic factor. Cell. 2013; 155:1596-609.

63. Elkabes S, DiCicco-Bloom EM, Black IB. Brain microglia/macrophages express neurotrophins that selectively regulate microglial proliferation and function. J Neurosci. 1996;16:2508-21.

64. Bredesen DE, Rabizadeh S. p75NTR and apoptosis: Trk-dependent and Trkindependent effects. Trends Neurosci. 1997;20:287-90.

65. Glazner GW, Mattson MP. Differential effects of BDNF, ADNF9, and TNFalpha on levels of NMDA receptor subunits, calcium homeostasis, and neuronal vulnerability to excitotoxicity. Exp Neurol. 2000;161:442-52.

66. Chao MV, Bothwell M. Neurotrophins: to cleave or not to cleave. Neuron. 2002;33:9-12.

67. Miguez-Burbano MJ, Espinoza L, Bueno D, Vargas M, Trainor AB, Quiros C, Lewis JE, Asthana D. Beyond the brain: the role of brain-derived neurotrophic factor in viroimmune responses to antiretroviral therapy among people living with HIV with and without alcohol use. J Int Assoc Provid AIDS Care. 2014;13:454-60.

68. Angelucci F, Ricci V, Pomponi M, Conte G, Mathe AA, Attilio Tonali P, Bria P. Chronic heroin and cocaine abuse is associated with decreased serum concentrations of the nerve growth factor and brain-derived neurotrophic factor. J Psychopharmacol. 2007;21:820-5.

69. Bachis A, Campbell LA, Jenkins K, Wenzel E, Mocchetti I. Morphine withdrawal increases brain-derived neurotrophic factor precursor. Neurotox Res. 2017;32:509-17.

70. Nosheny RL, Ahmed F, Yakovlev A, Meyer EM, Ren K, Tessarollo L, Mocchetti I. Brain-derived neurotrophic factor prevents the nigrostriatal degeneration induced by human immunodeficiency virus-1 glycoprotein 120 in vivo. Eur J Neurosci. 2007;25:2275-84.

71. Bachis A, Major EO, Mocchetti I. Brain-derived neurotrophic factor inhibits human immunodeficiency virus-1/gp120-mediated cerebellar granule cell death by preventing gp120 internalization. J Neurosci. 2003;23:5715-22.

72. Yang K, Perez-Polo JR, Mu XS, Yan HQ, Xue JJ, Iwamoto Y, Liu SJ, Dixon CE, Hayes RL. Increased expression of brain-derived neurotrophic factor but not neurotrophin-3 mRNA in rat brain after cortical impact injury. J Neurosci Res. 1996:44:157-64.

73. Oyesiku NM, Evans CO, Houston S, Darrell RS, Smith JS, Fulop ZL, Dixon CE, Stein DG. Regional changes in the expression of neurotrophic factors and their receptors following acute traumatic brain injury in the adult rat brain. Brain Res. 1999;833:161-72.

74. Lebrun-Julien F, Bertrand MJ, De Backer O, Stellwagen D, Morales CR, Di Polo A, Barker PA. ProNGF induces TNFa-dependent death of retinal ganglion cells through a p75NTR non-cell-autonomous signaling pathway. Proc Natl Acad Sci U S A. 2010;107:3817-22.

75. Kiprianova I, Freiman TM, Desiderato S, Schwab S, Galmbacher R, Gillardon F, Spranger M. Brain-derived neurotrophic factor prevents neuronal death and glial activation after global ischemia in the rat. J Neurosci Res. 1999:56:21-7. 
76. Roux PP, Colicos MA, Barker PA, Kennedy TE. p75 neurotrophin receptor expression is induced in apoptotic neurons after seizure. J Neurosci. 1999; 19:6887-96.

77. Dowling P, Ming X, Raval S, Husar W, Casaccia-Bonnefil P, Chao M, Cook S, Blumberg B. Up-regulated p75NTR neurotrophin receptor on glial cells in MS plaques. Neurology. 1999:53:1676-82.

78. Goutan E, Marti E, Ferrer I. BDNF, and full length and truncated TrkB expression in the hippocampus of the rat following kainic acid excitotoxic damage. Evidence of complex time-dependent and cell-specific responses Brain Res Mol Brain Res. 1998:59:154-64.

79. Mahajan SD, Schwartz SA, Shanahan TC, Chawda RP, Nair MP. Morphine regulates gene expression of alpha- and beta-chemokines and their receptors on astroglial cells via the opioid mu receptor. J Immunol. 2002;169:3589-99.

80. Szabo I, Chen XH, Xin L, Adler MW, Howard OM, Oppenheim JJ, Rogers T」. Heterologous desensitization of opioid receptors by chemokines inhibits chemotaxis and enhances the perception of pain. Proc Natl Acad Sci U S A. 2002;99:10276-81.

81. Hahn YK, Paris JJ, Lichtman AH, Hauser KF, Sim-Selley L, Selley DE, Knapp PE. Central HIV-1 Tat exposure elevates anxiety and fear conditioned responses of male mice concurrent with altered mu-opioid receptormediated G-protein activation and $\beta$-arrestin 2 activity in the forebrain. Neurobiol Dis. 2016;92:124-36.

82. Chen C, Li J, Bot G, Szabo I, Rogers TJ, Liu-Chen LY. Heterodimerization and cross-desensitization between the $\mu$-opioid receptor and the chemokine CCR5 receptor. Eur J Pharmacol. 2004;483:175-86.

83. Szabo I, Wetzel MA, Zhang N, Steele AD, Kaminsky DE, Chen C, Liu-Chen LY, Bednar F, Henderson EE, Howard OM, et al. Selective inactivation of CCR5 and decreased infectivity of R5 HIV-1 strains mediated by opioid-induced heterologous desensitization. J Leukoc Biol. 2003;74:1074-82.

84. Arnatt CK, Falls BA, Yuan Y, Raborg TJ, Masvekar RR, El-Hage N, Selley DE, Nicola AV, Knapp PE, Hauser KF, Zhang Y. Exploration of bivalent ligands targeting putative mu opioid receptor and chemokine receptor CCR5 dimerization. Bioorg Med Chem. 2016;24:5969-87.

85. Yuan Y, Arnatt CK, El-Hage N, Dever SM, Jacob JC, Selley DE, Hauser KF, Zhang Y. A bivalent ligand targeting the putative mu opioid receptor and chemokine receptor CCR5 heterodimers: binding affinity versus functional activities. Medchemcomm. 2013;4:847-51.

86. El-Hage N, Dever SM, Podhaizer EM, Arnatt CK, Zhang Y, Hauser KF. A novel bivalent HIV-1 entry inhibitor reveals fundamental differences in CCR5- $\mu$ opioid receptor interactions between human astroglia and microglia. AIDS. 2013;27:2181-90.

Ready to submit your research? Choose BMC and benefit from:

- fast, convenient online submission

- thorough peer review by experienced researchers in your field

- rapid publication on acceptance

- support for research data, including large and complex data types

- gold Open Access which fosters wider collaboration and increased citations

- maximum visibility for your research: over $100 \mathrm{M}$ website views per year

At BMC, research is always in progress.

Learn more biomedcentral.com/submissions 